Marketing and Branding Research

WWW.CIKD.CA

\title{
Adaptive Capability, Social Media Agility, Ambidextrous Marketing Capability, and Business Survival: A Mediation Analysis
}

\author{
Onamusi Abiodun Babatunde
}

Department of Management and Accounting, Lead City University, Ibadan, Oyo State, Nigeria

\section{Keywords: \\ Adaptive capability Social media agility, Ambidextrous marketing capability, Business survival}

\section{Received}

28 December 2020

Received in revised form

01 January 2021

Accepted

02 January 2021

*Correspondence:

abiodunonamusi@gmail.com

\begin{abstract}
This study assessed the effect of adaptive capability and social media agility on survival firms in multiple industries in five countries. Furthermore, it established the mediating effect of ambidextrous marketing capability on the interaction between adaptive capability, social media agility, and firm survival, and examined the interaction between social media agility and adaptive capability. The study adopted a survey design and a sample of 416 firms in Nigeria, Canada, the United States, Australia, and the United Kingdom, and conducted the regression analysis to test the hypotheses formulated therein. The results showed that adaptive capability and social media agility had a positive and significant effect on business survival. Further analysis showed that when ambidextrous marketing capability was incorporated into the two models respectively and forming multiple regression analysis, the coefficient of ambidextrous marketing capability had a significant effect on business survival; however, the coefficient of adaptive capability and social media agility became insignificant suggesting that a full mediation effect was established. Lastly, social media agility had a positive and significant effect on the firm's adaptive capability. The findings suggest that adaptive capability and social media agility enhance firm survival through the mechanism of ambidextrous marketing capability. The study recommends that firms strengthen their adaptive capability infrastructure; develop a robust, agile social media interface, and commit resources to enhance connectivity with the market, supplier, and customers (outside-in). Likewise, enhance internal organizational knowledge, skill, and ability (inside-out) to offer incremental and radical products to address changing market demand.
\end{abstract}

One new economic reality for many nations, firms, and governments worldwide is the coronavirus pandemic's attendant consequences. The new reality is far from what humanity considered typical, barely twelve months before the virus's first reported case in Wuhan, China, in December 2019. Specifically, the world has seen massive economies lockdowns, economic recessions unfolding in 
multiple countries, production shutdowns, mobility restrictions, hundreds of thousand deaths, millions of job losses, untold hardship for developing countries ravaged by wars, political unrest, poverty, disease, and those that overly depend on crude oil for its national revenue and the predictions of a famine of biblical proportions (World Health Organization (WHO), 2020). In this period of grave uncertainty, it is imperative to begin to look for means through which humanity and business can manage/cope with this current reality to survive. This is because the cost attributable to this pandemic if the status quo remains and countries continue to be on systematic lockdown, is highly likely to cause hunger and death to millions of humans and organizations (Soludo, 2020; WHO, 2020).

In strategic management literature, scholars have considered issues ranging from different firmlevel capabilities to help firms achieve significant performance in the turbulent environment (Kaur, Chahal, \& Gupta, 2018; Mohammed, Norshahrizan, \& Wan-Ahmad, 2017; Mu, Bao, Sekhon, Qi, \& Love, 2018; Mukhtar, Rosli, \& Azizi, 2017; Onamusi, 2020). However, this disruption to the global economy has not been considered in many empirical and theoretical studies. Given the issues discussed so far, one firm-level capability that comes to mind is an adaptive capability derived from the dynamic capability theory narratives. Since the pandemic did not offer much liberty (like many external environmental factors), firms must develop the capability to adapt to this externality; otherwise, they may not survive (an argument pushed forward by the external environment analyst). To meet customers' expectations within the limit defined by this pandemic, a firm must possess agile social media to enhance how it can quickly interface with its customers and operationalize its adaptive capability strategy.

Despite the restrictive nature of the COVID-19 pandemic and its destructive potentials to businesses globally, it equally offers immerse productive potential to local business firms who can quickly take advantage of its present business opportunities. Hence, firms that possess ambidextrous capability may survive turbulent times profitably. Conceptually having ambidextrous capability offers businesses the rare opportunity to combine two extreme capabilities, exploitative and explorative capabilities, and achieving a better chance of surviving turbulent times. Taking a cue from Day (2020), an example of this dualism is explained naturally by the Ikogosi warm water spring in Ekiti State in Nigeria, where two streams, Hot and Cold, come together to create a warm spring enjoyed by tourist and form one of the wonders of the world. According to Day (2020), this dualism describes how seemingly contrary forces are complementary and interrelated to produce an unusual outcome. With the exploitative capability, a firm can extend its product options, such as developing new products and creating a new market or creating new customers in an existing market (tag Outside-in). On the other hand, the explorative capability allows a firm to discover and explore new options such as diversifying into new business portfolios different from what it used to (tag Inside-out). Hence, the alignment of these extreme capabilities creates an organization that, via outside-in, asks and collects information from the market-agents and, via its in-side out capability, can deliver on the value that consistently meets changing market demand (Day, 2020).

Existing empirical studies ( $\mathrm{Mu}$ et al., 2018) have independently considered ambidextrous capability in marketing capability; the studies have helped explain how the firm can adopt these capabilities as a competitive strategy. Moreover, explaining the boundary conditions within which marketing capability can enhance the achievement of significant performance. Also, Mehrabi, Coviello, and Ranaweera (2019) substantiated the relevant role of entrepreneurial orientation in 
enhancing the performance effect of ambidextrous capability in marketing. Ho, Osiyevskyy, Agarwal, and Reza (2020) considered the moderating role of absorptive capability on the interaction between ambidextrous marketing capability and sale growth. In a merely different direction, Frau, Moi, and Cabiddu (2020) addressed the limitation of earlier studies (Barney, 2014; Chong, Bian, \& Zhang, 2016; Conduit, Matanda, \& Mavondo, 2014; Kozlenkova, Samaha, \& Palmatier, 2014) by undertaking a qualitative longitudinal study to provide an in-depth analytical framework to position the distinctive characteristics of the ambidextrous marketing capability. However, since these studies (Barney, 2014; Chong et al., 2016; Conduit et al., 2014; Frau, Moi, \& Cabiddu, 2020; Ho et al., 2020; Kozlenkova et al., 2014; Mehrabi et al., 2019; Mu et al., 2018) did not consider these capabilities within an adaptive capability and social media agility perspective for surviving the COVID-19 pandemic, it creates a need in the literature to be explored. Furthermore, the gap limits our empirical understanding of the relevance of ambidextrous marketing capability for firms trying to use its adaptive capability and social media agility to achieve their survival chances.

The present study examines the interaction between adaptive capability and business survival; also, it evaluates the mediating effect of ambidextrous marketing capability on the interaction between adaptive capability and business survival. Also, the functional relationship between social media agility and business survival is evaluated. Lastly, the study establishes the mediating effect of ambidextrous marketing capability on the link between social media agility and business survival.

\section{Literature Review}

\section{Theoretical Framework and Hypotheses Development}

This study draws on the Dynamic Capability Theory (DCT) to provide a theoretical explanation to substantiate the interactions between adaptive capability, social media agility, ambidextrous marketing capability, and firm survival. Been an outside-in and inside-out perspective, the dynamic capability theory creates the mechanism through which a firm can achieve superior performance under changing and uncertain environments (Kaur \& Mehta, 2017; Laaksonen \& Peltoniemi, 2016; Mu, 2017). According to dynamic capability scholars (Teece, 2014a; Teece, Pisano, \& Shuen, 1997; Wu \& Vahlne, 2020), possessing the knowledge, skill, and ability to adapt, absorb and innovate critical internal and external competences, and constantly reconfigure these competencies to accommodate environmental changes is the critical success factor for achieving business continuity and superior performance in a highly dynamic environment. Besides, at the heart of the dynamic capability theory is the adaptive capability mechanism (Kaur \& Mehta, 2017), which emphasizes that firms desirous of sustaining their going-concern status within a turbulent environment must learn to adjust to the changes prevailing in the environment quickly. Additionally, firms must learn to absorb (Hou \& Chien, 2010; Monferrer, Blesa, \& Ripollés, 2015) critical information from the changing environment through outside-in capability and the inside-out capability because they both aid the firm's ability to offer innovative products that align with the changing environment. It is also noteworthy to stress that social media agility also falls within the scope of dynamic capability because agility, as used here, connotes a firm with strategic foresight, insight, information telecommunication infrastructure, internal and external response competencies (Arokodare, Asikhia, \& Makinde, 2019) regarding its social media engagement within and outside the organization.

This study argues that considering adaptive capability and social media agility can be consistently reconfigured to meet environmental dynamics; hence, firms that deploy these 
competencies would achieve superior performance. The fit-as-mediator perspective suggests that when the indirect effect between two variables is explained by a third, then a mediation effect is achieved. Therefore, this study proposes that: firms who can deploy the adaptive capability and social media agility will experience a significant effect on firm survival; and that the deployment of social media agility will enhance the firm's adaptive capability because of how it can be a critical source of market and customer feedback which boosts the firm's capacity to adapt. Lastly, the study proposes that the individual interaction between adaptive capability and social media agility on business survival would be mediated by ambidextrous marketing capability.

\section{Empirical Review}

\section{Adaptive Capability and Firm survival}

The need to continue to operate successfully is usual one objective many organizations seek to achieve during significant macro-environmental challenges. Given the level of unplanned and unanticipated changes and their attendant consequences for firm operations, the dynamic capability theory's proponent stressed the need for a firm to possess an adaptive capability. The implication of possessing such capability is that it offers the organization the ability to stabilize its operation to soothe the macro-environment changes while strategically thinking of other options to consider. Oktemgil and Greenley (1997) stressed that adaptability is equally crucial as firms with high adaptive capability enjoy better performance outcomes than slow adapters, which creates the basis for market leadership, challengers, and followers. Although this sound conceptually and theoretically appropriates, it is essential to find other empirical positions to substantiate the effect adaptive capability has for business continuity.

Accordingly, scholars have submitted that an adaptive capability is a significant prerequisite for firm survival (Chryssochoidis, Dousios, \& Tzokas, 2016; Kelly, Kelliher, Power, \& Lynch, 2020; $\mathrm{Zhu}, \mathrm{Su}, \& \mathrm{Shou}, 2017)$. On the factor that enhances adaptive capability, Eshima and Anderson (2016) pointed out that growth in firm resources, to a large extend, exposes the organization to changing market conditions, which consequently improves the firm's adaptability. Also, Kelly et al. (2020) posited that firms who possess proactive operational capability are highly likely to develop an adaptive capability. The scholar further underscores the relevance of the adaptive capability to gain continuous business profitability streams, which guarantees business continuity. Kelly et al.'s (2020) implication is that the adaptive capability is a derivative of a strategic thinking process that is deliberate about reconfiguring the existing firm-resource base, which by no means occurs accidentally. Kelly's position corroborates the submission of prior studies such as Eshima and Anderson (2016) and Kelliher, Kearney, and Harrington (2018). Through their study, Zhu, Su, and Shou (2017) revealed that adaptive capability and supplier opportunism act as mediators between social ties and firm survival. They stressed that "a firm's adaptive capability and the suppression of supplier opportunism are essential for survival and success in emerging economies.

Chryssochoidis, Dousios, and Tzokas (2016) draw relevance for small firm adaptive capability within small business firms. According to the scholars, via a moderated and mediated analysis, the path linking small firm competitive strategy and performance is enhanced and explained through small firm adaptive capability. On which underlining mechanism explains how the highperformance work system (HPWS) enhances organizational outcomes, Wei and Lau (2010) investigated the Chinese firms' sample. Through its finding, the study suggested that the interaction 
between HPWS and firm performance is partially explained within the mechanism of the adaptive capability. Given the relevance of adaptive capability discussed so far, the study proposed that adaptive capability deployment would significantly enhance firm survival in a turbulent environment.

\section{Social Media Agility and Firm Survival}

In the event of unprecedented market dynamics, where customers exhibit erratic behavior and competition becomes aggressive, it becomes critical for firms to gather customer-intelligence that would enhance their ability to respond to the market need more effectively (Chuang, 2020; Hardwick \& Anderson, 2019; Koponen, Julkunen, \& Asai, 2019; Mpandare \& Li, 2020; Murphy \& Sashi, 2018; Quach, Thaichon, Lee, Weaven, \& Palmatier, 2020). Otherwise, failure to be responsive to this competitive market dynamics suggests a firm that is not interested in being competitive nor wanting to survive the harsh business environment. As suggested by scholars, one way to quickly reach out to the customer is by adopting social media platforms (BulliniOrlandi, Zardini, \& Rossignoli, 2020; Christodoulides, Michaelidou, \& Siamagka, 2019; Nunan, Sibai, Schivinski, \& Christodoulides, 2018; Ogilvie, Agnihotri, Rapp, \& Trainor, 2018). As a customer-related tool, social media can remotely enable customers to connect with the firm to exchange information and obtain feedback that will improve the firm in terms of goods and services on offer (Harrigan, Miles, Fang, \& Roy, 2020; Wang, Zhang, Tse, \& Chan, 2020). This helps foster customer relations, improving customer equity (Carr, Drennan, \& Andrews, 2016), customer trust, and brand attachment (Kim, Kim, \& Hwang, 2020; Li, Teng, \& Chen, 2020). While this narrative may be correct, employing social media and not being agile in customer feedback may not guarantee the positive ripple effect as identified earlier. This is because a lack of agile social media suggests that a firm that cannot identify changing market demands attributable to erratic customer feedback quickly and proactively takes advantage of the opportunities it provides and responds efficiently by providing a market offering that meets customer feedback (Chuang, 2020). Besides, Nijssen and Ordanini (2020) stressed that using social media to create a new product for customers is not an isolated activity because its success is preconditioned on how such external feedbacks are effectively integrated within existing firm-level capabilities.

Extant literature has found relevance for social media agility in enhancing business performance. For example, Martín-Rojas et al. (2020) used a sample of firms in the technology sector submitted that social media enhance increase connectivity with relevant market agents and leverage knowledge gained over time to improve organizational performance. On how social media agility can aid internal organizational process and innovation performance, Ali, Bahadur, Wang, Luqman, and Khan (2020), pointed out that through social media engagement at work, a firm's absorptive capacity is influenced greatly to acquire, segregate and assimilate external knowledge. The ripple effect allows for efficient transformation and utilization of such knowledge acquired in team innovation performance. Similarly, using a sample of Hotels, Garrido-Moreno, García-Morales, King, and Lockett (2020) did not find a first-order effect on social media agility interaction and performance. Instead, their findings established a mediating relationship, which suggests that the interaction between customer engagement capabilities and performance was explained through social media interphase.

Several studies have found relevance for agility in different topical areas of management, such as in supply chain management, the internet of things, customer engagement, and technologydriven operational management (Akhtar, Khan, Tarba, \& Jayawickrama, 2018; Chuang, 2020; 
Swafford, Ghosh, \& Murthy, 2008; Tan, Tan, Wang, \& Sedera, 2017) and its usage in this study followed it inter-disciplinary relevance of the concept of agility to firm success. Given this discussion, this study proposes that social media agility will explain significant firm survival variations.

Also, this study argues that agile social media can strengthen an organization's adaptive tendencies. This is because, during changing market demands attributable to erratic customer behavior, social media agility can help firms to understand the changing market trends quickly and subsequently collect market feedback, which firms can use to cope in the short run with the market dynamics. The relevance of social media agility in customer co-creation, knowledge acquisition, supply-chain management, and customer equity suggests that it can boost a firm's ability to adapt to changing market demands. On this narrative's strength, this study proposes that the deployment of social media agility will significantly enhance a firm's adaptive capability.

\section{The Mediating Effect of Ambidextrous Marketing Capability}

Resonating the RBV narratives, a firm's ability to succeed lies in its capability to concentrate on allocating its resources to offer a unique value proposition (Grant, 1996); one such capability is marketing competencies. Onamusi (2020) posited that MC is a multidimensional concept, which incorporates firm-level resources (Knowledge, Skill, and Ability). It integrates cross-functional activities within the organization to contend with market demands/trends through outside-in capabilities and take advantage of the market opportunities through inside-out capabilities to create a unique value proposition that can improve the organizational capacity to be a competitive and profitable going concern. The desire to comprehend the principles and the ripple effects of marketing capability led to several empirical studies in marketing strategy (Day, 2014; Kumar, 2015; Mu et al., 2018; Musarra \& Morgan, 2020; Sun et al., 2019). Mu et al. (2018), conceptualized the Outside-in marketing capability as a marketing orientation that seeks to solve marketing problems by seeking information from the market (outside of the organization) on what it requires, how it requires it, and when to deliver. Outside-in marketing capability is reactive because of the firm responses to what the market dictates. Capabilities such as market-sensing, partner-linking, market communication, pricing, selling, market planning, and implementation are the subdimensions of Outside-in marketing capability (Day, 2011; Mu et al., 2018).

On the other hand, according to Day (2011), the Inside-out capability allows a firm to use its inherent abilities and subsequently ask what the market can do. More like offering a product the market never requested and hoping it would buy when offered to it. This was a traditional business perspective. However, as soon as the perspective of the consumer being 'King' came up, it became imperative for a firm to adjust to consumer demand, considering that the inside-out capabilities restrict their ability to adapt to profoundly changing market conditions (Day, 2011; Day \& Moorman, 2010; Kaur et al., 2018). A more recent discussion in marketing studies is the alignment of the Outside-in and the inside-out to suggest ambidextrous capability termed as a blended marketing strategy (Frau, Moi, \& Cabiddu, 2020), which helps in creating a better value proposition given the synergy of two extreme capabilities (Day, 2020).

Although $\mathrm{Ho}$ and $\mathrm{Lu} 2015$ ) found that market-oriented firms who engage in high-level ambidextrous capability in new product development achieved better performance; however, firms must be cautioned in the pursuance of ambidextrous marketing capability. This is because, in a 
survey of Singapore, firms who pursued a high-level blended capability at once ended up achieving lower performance compared to competing firms who did not. This submission emphasizes the complexity and challenges of balancing the outside-in and inside-out marketing capability within the same organizational framework. Ho and Lo (p. 2015) explained that because of the number of resources required, if the organization decided to pursue both strategies concurrently, it may stress both the firm's resources and management focus, weakening the firm's effectiveness and efficiency in achieving significant market performance.

Further analysis by $\mathrm{Ho}$ and $\mathrm{Lu}$ (2015) revealed that outside-in marketing capability (exploitation) contribute strongly, positively and significantly to firm's market performance, however, the scholars found contrary result for inside-out marketing capability because the capability had no significant effect on firm market performance. This insignificant effect finding is unexpectedly giving the quantum of prior empirical studies that have underscored the relevance of inside-out capability to enhancing firm competitiveness in a turbulent market environment ( $\mathrm{Mu}$, 2015; Ho, Osiyevskyy, Agarwal, \& Reza, 2020).

Regarding the mediating effect of ambidextrous capability on the interaction between firm-level capabilities and firm performance. $\mathrm{Mu}$ (2015) posited that exploitation and exploration respectively mediated the association between marketing capability and NPD performance and that marketing capability helps the firm's adaptive capability performance. Ho et al.'s (2020) submission provided reasons to believe that market ambidexterity indirectly affects sale growth. Further analysis suggested that firms who can achieve blended marketing capability enjoy better market performance than those who engage only in a set of strategy (only exploitative strategy)

$\mathrm{Mu}$ et al. (2018), in mediation analysis, shows that outside-in marketing capability is a critical source of superior performance as it served as the mechanism through which outside-in marketing capability influence firm performance. $\mathrm{Mu}$ et al. (2018) stated that outside-in marketing capability enhances the development of internal response marketing capability and flexible allocation of resources to contend with erratic market demands. This interaction seems to be a precondition to achieving high customer value, which influences superior market performance. Providing support for Mu et al.'s (2018) submission, Mehrabi, Coviello, and Ranaweera (2019) underscored the relevance of combined ambidexterity (as against balanced) in enhancing market performance. However, further analysis revealed that imbalance ambidexterity in marketing capability negatively affects market performance; an outcome shared by Wei et al. (2014) but rejected by other scholars who, through their study, argue that such imbalance, does not always create a negative outcome (Josephson et al., 2016; Junni et al., 2013).

Although the significance of the earlier scholars' submission helped in understanding the performance effect of ambidextrous marketing capability nevertheless, given the contextual difference between these prior studies and the present study, the path linking adaptive capability, social media agility, and firm survival remained unexplained. The conceptual logic here is that firms that possess adaptive capability should be able to withstand turbulent environmental factors, and the interaction can be explained through the deployment of ambidextrous marketing capability. Because the ambidextrous marketing capability helps a firm to consistently gather data from the market characterized by varying consumer demands and its inside-out capability, it offers products that satisfy changing market demand. Therefore, the study hypothesizes that: ambidextrous marketing capability possesses a significant moderating effect on the interaction between adaptive capability and business survival. 
This study also argues that the boundary condition through with social media agility influences firm survival can be explained through ambidextrous marketing capability. In other words, the deployment of the outside-in and inside-out marketing capability will explain and enhance how social media agility enhances business survival. This is because social media agility goes beyond being a platform for voluntary customer feedback to become the marketplace. As such, how agile a firm's social media is a function of how knowledgeable the organization is about what the market needs (this is achieved through outside-in capability) and on how well the organization can muster internal competency (this is achieved through inside-out capability) to create a market offering with a unique value proposition. Based on this premise, the study hypothesizes that ambidextrous marketing capability has a significant indirect effect on the interaction between social media agility and business survival.

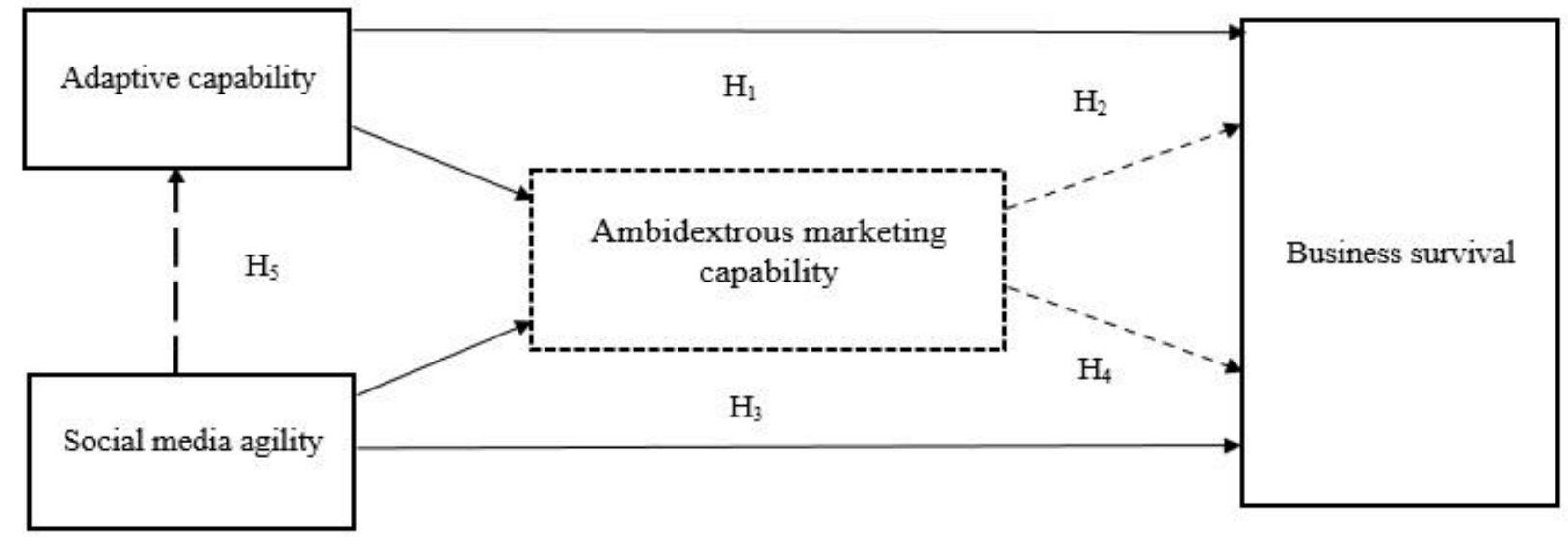

Figure 1. Conceptual model

The conceptual model in Figure 1 provides a pictorial explanation for the research questions asked and the concomitant hypotheses developed in this study. The research questions include:

1. What is the effect of adaptive capability on business survival?

2. How does ambidextrous marketing capability mediate the interaction between adaptive capability and business survival?

3. What is the effect of social media agility on business survival?

4. What is the mediating effect of ambidextrous marketing capability on the relationship between social media agility and business survival?

5. How does social media agility influence adaptive capability?

Following the research questions, the hypotheses tested are as follows:

H1: Adaptive capability has a significant influence on business survival.

$\mathbf{H}_{2}$ : Ambidextrous marketing capability significantly mediates the interaction between adaptive capability and business survival.

H3: Social media agility has a significant effect on business survival.

H4: Ambidextrous marketing capability significantly mediates the relationship between social media agility and business survival.

H5: Social media agility significantly influences the firm's adaptive capability. 


\section{Methods}

\section{The Study Context, Sampling, and Data collection}

This study adopted a quantitative method using the cross-sectional survey research design and this helps the collection of data at a point in time to substantiate the interaction between adaptive capability, social media agility, ambidextrous capability, and business survival.

This study's population comprises an infinite number of organizations in Nigeria, Canada, the United Kingdom, the United States, and Australia. The organizations include manufacturing companies in FMCGs, packaging, pharmaceutical and agro-allied, quick service restaurant, insurance, banking, logistics, Online/Offline stores, telecommunication, small and medium enterprises, and the oil and gas companies. Cochran (1963) provided an optimum sample size in an infinite population of the study, $384.10 \%$ of this sample size (38) was calculated and added to the scientifically determine sample size $(384+38=422)$ to ensure that response obtained did not fall below the optimum sample size. Four hundred twenty-two companies took part in this study; however, respondents who indicated a weak level of confidence in the responses provided in this study were excluded. In all, 398, which represented a $94.3 \%$ response rate was achieved.

The research instrument for data collection was a structured questionnaire considered relevant in collecting feedback based on the respondents' opinion, and it is suitable for collecting data within a short time on current issues. The adapted questionnaire had thirty-two (32) items. Adaptive capability had seven (7) items, social media agility had six (6) items, ambidextrous marketing capability had six (6) items for Outside-in capability and seven (7) items for Inside-out capability making a total of thirteen (13) items, and business survival had six (6) items. The adapted questionnaire (see measurement of variables) was a standardized scale that has been used by authors on the subject matter of this research in another research context. The response options provided in this study's questionnaire followed the Likert-type scale which ranges from strongly disagree to strongly agree. With the aid of the Google form and electronic mail system, the questionnaire's administration and retrieval took eight weeks of consistent reminders to the respondents. The Google form application offered immense analytical opportunity given how the filled questionnaires were quickly transformed to excel spreadsheet data and subsequently into SPSS data set where the analysis was conducted.

\section{Measurement of Variables}

Drawing from this study's research framework, the following independent (adaptive capability and social media agility), mediating (ambidextrous marketing capability), and dependent (business survival) variables were discussed, taking into consideration their measurement in extant literature. This study in concomitant with previous scholars ( $\mathrm{Mu}$ et al., 2018) employed the use of a multi-item scale to measure each construct in this study. However, the established multi-item scale was adapted from prior studies to suit the context of this study.

The adaptive capability reflects how flexible a firm is in acclimatizing to significant changing market demands, comes from scholars such as Lu, Zhou, Bruton, and Li (2010) and Zhu, Su, and Shou, (2017). Social media agility was also measured based on Chuang's (2020) conceptualization, which incorporated internal and external social media agility dimensions. Ambidextrous marketing capability involved multidimensional tasks and was measure by incorporating exploitative and exploratory marketing activities ( $\mathrm{Mu}, 2015$; $\mathrm{Mu}$ et al., 2018). Business survival refers to the organization's ability to consistently achieve significant performance on a going-concern basis. Firm survival was measured by integrating financial and non-financial dimensions on a multi-item scale 
(Anning-Dorson, 2018; Najafi-Tavani et al., 2018). Overall, this study's variables identified were measured in concomitant with the measures discussed above, and they were collected through the use of questionnaires as achieved by earlier authors.

\section{Data Analysis and Model Specification}

The study employed multiple regression analysis to establish the indirect effect of ambidextrous marketing capability on the individual effect of adaptive capability and social media agility on business survival.

$\mathrm{Y}=\mathrm{f}(\mathrm{X})$

$Y=$ Dependent variable: Business Survival (BS)

$X=$ Independent variables: Adaptive capability (AC) and Social media agility (SMA)

$\mathrm{Z}=$ Mediating variable: Ambidextrous marketing capability (AMC)

This study followed Baron and Kenny's (1986) three steps identified below.

One: Adaptive capability, ambidextrous marketing capability, and business survival:

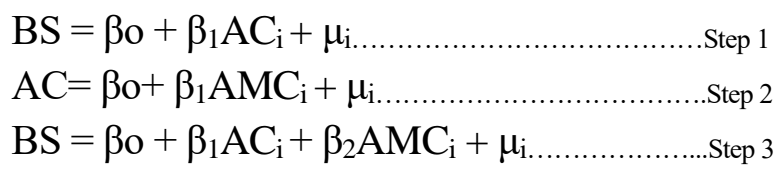

Two: Social media agility, ambidextrous marketing capability, and business survival:

$\mathrm{BS}=\beta \mathrm{o}+\beta_{1} \mathrm{SMA}_{\mathrm{i}}+\mu_{\mathrm{i} \ldots \ldots \ldots \ldots \ldots \ldots \ldots \ldots \ldots \ldots \ldots \text {. } \ldots \ldots \ldots \ldots} 1$

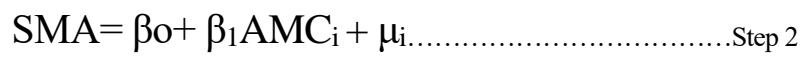

$\mathrm{BS}=\beta \mathrm{o}+\beta_{1} \mathrm{SMA}_{\mathrm{i}}+\beta_{2} \mathrm{AMC}_{\mathrm{i}}+\mu_{\mathrm{i}} \ldots \ldots \ldots \ldots \ldots \ldots$....... 3

To analyze the effect of social media agility on adaptive capability:

$\mathrm{Y}=\mathrm{f}(\mathrm{X})$

$Y=$ Dependent variable: Adaptive capability (AC)

$X=$ Independent variables: Social media agility (SMA)

$\mathrm{AC}=\beta \mathrm{o}+\beta_{1} \mathrm{SMA}_{\mathrm{i}}+\mu_{\mathrm{i}}$

Equation

\section{Result}

\section{Validity and Reliability Test}

To ensure that the instrument is valid and reliable, factor analysis and internal consistency analysis was conducted. The process leading to validity suggests that Kaiser-Meyer-Olkin which measures the suitability of the study's data and the sampling adequacy for each variable in the model and Bartlett test of sphericity statistics must be within acceptable thresholds. In this study, the KaiserMeyer-Olkin statistic ranges between .79 and .81 for variables measured, and since the values were greater than .70 threshold and the Bartlett test probability value was less than .05 for all the variables, suggests that the data is suitable for factor analysis. Factor loadings of items measuring a variable are considered key to determining the Average Variance Explained (AVE) and the Composite Reliability (CR). Through the varimax extraction method, factor loadings extracted for each item measuring the study's variables were above the .70 threshold. In all, Table 1 presents a summary of the validity and reliability statistics of the study variables. The results showed that the 
adaptive capability, social media agility, ambidextrous marketing capability, and business survival AVE, CR, and Cronbach's Alpha (CA) values above the threshold of .5, .7, and .7 respectively which suggest that the instrument is valid and reliable for this study.

Table 1

Validity and Reliability Test for Measurement Items

\begin{tabular}{llll}
\hline Latent Variables & CA & CR & AVE \\
\hline Adaptive capability & .87 & .88 & .68 \\
Social media agility & .96 & .95 & .76 \\
Ambidextrous marketing capability & .94 & .92 & .59 \\
Business survival & .93 & .91 & .65 \\
\hline
\end{tabular}

Table 2 presents the descriptive statistics and the correlation analysis for all the variables in this study. For the descriptive statistics, the mean values, which range from 4.41 to 4.90 , showed that, on average, respondents agreed to the items measuring adaptive capability, social media agility, ambidextrous marketing capability, and firm survival. The resulting standard deviation equally shows that, on average, respondents' opinions were not far apart. The Pearson Product Moment Correlation coefficient shows a linear relationship between predictor variables and the outcome variable in this study.

Table 2

Mean, Standard Deviation and Correlation for all Variables

\begin{tabular}{lcccccc}
\hline Variable Name & & $S D$ & $\begin{array}{c}\text { Adaptive } \\
\text { capability } \\
(\mathrm{r})\end{array}$ & $\begin{array}{c}\text { Social media agility } \\
(\mathrm{r})\end{array}$ & $\begin{array}{c}\text { Ambidextrous } \\
\text { marketing capability } \\
(\mathrm{r})\end{array}$ & $\begin{array}{c}\text { Firm survival } \\
(\mathrm{r})\end{array}$ \\
\hline Adaptive capability & 4.90 & .77 & 1 & $.57^{* *}(.001)$ & $.73^{* *}(.001)$ & $.52^{* *}(.001)$ \\
Social media agility & 4.70 & 1.09 & & 1 & $.65(.26)$ & $.50^{* *}(.001)$ \\
Ambidextrous & 4.83 & .76 & & 1 & $.66^{*}(.001)$ \\
marketing capability & 4.41 & 1.02 & & & 1 \\
Firm survival & Note: Correlation is significant at the .01 level (2-tailed).
\end{tabular}

\section{Hypotheses Testing}

Table 3 presents the model summary of regression analysis for the mediating effect of ambidextrous capability in marketing on the respective functional relationship between adaptive capability and social media agility on business survival, and the effect of social media agility on adaptive capability. In the first step (Model 1), the effect of adaptive capability on business survival was examined. In the Second step (Model 2), the effect of ambidextrous capability on adaptive capability was examined, and in the third step (Model 3), the relative effect of adaptive capability and ambidextrous capability on business survival was examined. Also, model 4 evaluated how social media agility influenced business survival. Model 5 assessed the influence of ambidextrous capability on social media agility. Model 6 determined the relative effect of social media agility and ambidextrous capability on business survival and discussed in three paragraphs below. Lastly, in model 7, the effect of social media agility on adaptive capability was analyzed.

In the first step (Model 1 and 4), a simple regression analysis was conducted, and the $\mathrm{R}^{2}$ was used as the determinant of the effective relationship. From the analysis, in model 1, it was discovered that adaptive capability accounted for $27.3 \%$ of the variance recorded in business survival $\left(\mathrm{R}^{2}=.27\right.$, $\mathrm{F}(1,215)=43.10, p=.001$ ), while the remaining $72.7 \%$ is explained by extraneous variables not considered in this study. The ßeta coefficient of determination showed that a unit change in adaptive capability increased business survival by .69 , and the corresponding t-value and probability values showed the influence was statistically significant $(\beta=.69, t=6.56, p=.001)$. Similarly, in model 4 , it was discovered that social media agility explained $25.2 \%$ of the variance recorded in business survival 
$\left(\mathrm{R}^{2}=.25, \mathrm{~F}(1,215)=38.67, p=.001\right)$, while the remaining $74.8 \%$ is explained by other variables not included in this study. The ßeta coefficient of determination showed that a unit change in social media agility increased business survival by .46 , and the corresponding t-value and probability values showed the influence was statistically significant $(\beta=.46, t=6.21, p=.001)$. The first precondition to conduct a mediation analysis suggested that the initial functional relationship between a predictor variable and an outcome variable must present a significant effect, this study fulfilled this first precondition. In the second step (Model 2 and 5), a simple regression analysis was conducted. From the analysis, it was discovered that in model 2, ambidextrous capability accounted for $53.9 \%$ of the changes recorded in adaptive capability $\left(\mathrm{R}^{2}=.53, \mathrm{~F}(1,216)=135.58, p=.001\right)$, while the remaining $46.1 \%$ is explained by extraneous variables not considered in this study. The $\beta$ eta coefficient of determination showed that a unit change in ambidextrous capability resulted in a .74 increase in adaptive capability, and the corresponding t-test and probability values showed the influence was statistically significant $(\beta=.74, t$ $=11.64, p=.00$ ). Also, model 5 shows that ambidextrous capability accounted for $42.4 \%$ of the changes recorded in social media agility $\left(\mathrm{R}^{2}=.42, \mathrm{~F}(1,216)=85.47, p=.001\right)$, while the remaining $57.6 \%$ was explained by extraneous variables not considered in this study. The $\beta$ eta coefficient of determination showed that a unit change in ambidextrous capability resulted in a .93 increase in social media agility, and the corresponding $\mathrm{t}$-value and probability values showed the influence was statistically significant $(\beta=.93, t=9.24, p=.001)$. The second precondition in the process of conducting a mediation analysis suggests that ambidextrous capability must have a statistically significant effect on adaptive capability and social media agility, respectively. This study fulfilled this second precondition.

In the third step (Model 3 and 6), multiple regression analysis was conducted, and the Adjusted $\mathrm{R}^{2}$ was employed as the determinant of the effect relationship given the presence of multiple predictor variables. Model 3 result revealed that adaptive capability and ambidextrous capability explained $43.6 \%$ variation experienced in business survival (Adj. $\mathrm{R}^{2}=.43, \mathrm{~F}(2,214)=45.76, p=.001$ ), while the remaining $56.4 \%$ was explained by variables not included in the regression model. The $\beta$ eta coefficient of determination showed that a unit change in adaptive capability increased business survival by .07 , and the corresponding t-value and probability values showed the influence was insignificant $(\beta=.07, t=.54, p=.58)$. However, the relative effect of ambidextrous capability shows that based on the $\beta$ eta coefficient of determination, a unit change increased business survival by .83 , and the corresponding $\mathrm{t}$-value and probability values showed the influence was significant $(\beta=.83, t=$ $5.95, p=.001)$.

Further analysis in Model 6 revealed that social media agility and ambidextrous capability explained $44.1 \%$ variation experienced in business survival (Adj. $\mathrm{R}^{2}=.44, \mathrm{~F}(2,214)=46.79, p=.001$ ), while the remaining $55.9 \%$ was explained by variables not included in the regression model. The $\beta$ eta coefficient of determination shows that a unit change in social media agility increased business survival by.10, and the corresponding t-value and probability values showed the effect was insignificant $(\beta=.10, t=1.19$, $p=.23$ ). However, the relative effect of ambidextrous capability based on the $\beta$ eta coefficient of determination showed that a unit change increased business survival by .79, and the corresponding tvalue and probability values showed the effect was statistically significant $(\beta=.79, t=6.43, p=.001)$.

The third mediation precondition, according to Baron and Kenny (1986), suggested that where a new predictor variable (ambidextrous capability) is introduced into the regression in model 1 and 3 changing it into a multiple regression model, the initial significant $\beta$ coefficient effect in model 1 and 3 becomes insignificant or disappears. If this assumption holds, then a full mediation (indirect effect) 
effect is achieved. Hence, from model 1 and model 6, the study achieved the three preconditions for a mediate analysis. Thus, it establishes that ambidextrous capability fully mediates the interaction between adaptive and business survival. On the one hand, likewise, ambidextrous capability fully mediates the interaction between social media agility and business survival. In both cases, the indirect effect is positive and statistically significant.

Lastly, model 7 established that social media agility explained $33.2 \%$ variation in adaptive capability $\left(\mathrm{R}^{2}=.33, \mathrm{~F}(1,216)=57.77, \mathrm{p}=.001\right)$, while the remaining $66.8 \%$ was explained by extraneous variables not included in the regression model of this study. The $\beta$ eta coefficient of determination showed that a unit change in social media agility increased adaptive capability by .40 , and the corresponding $\mathrm{t}$-value and probability values showed the effect was positive and significant $(\beta=.40, t$ $=7.60, p=.001)$.

Table 3

Summary of Regression Analysis for the Mediating Effect of Ambidextrous Capability in Marketing on the Respective Functional Relationship Between Adaptive Capability ${ }^{1,2,3}$ and Social Media Agility ${ }^{4,5,6}$ on Business Survival, and the Effect of Social Media Agility on Adaptive Capability ${ }^{7}$

\begin{tabular}{|c|c|c|c|c|c|c|c|c|}
\hline Model $^{1-3,4-6,7}$ & $\beta$ & $t$ & $p$ & $R$ & $R^{2}$ & Adj. $R^{2}$ & $\mathrm{~F}(\mathrm{df})$ & ANOVA \\
\hline${ }^{1}$ (Constant) & 1.03 & 1.98 & .05 & $.52^{\mathrm{a}}$ & .27 & .26 & $43.10(1,215)$ & .001 \\
\hline Adaptive capability & 0.69 & 6.56 & .00 & & & & & \\
\hline${ }^{2}$ (Constant) & 1.31 & 4.19 & .001 & $.73^{\mathrm{a}}$ & .53 & .53 & $135.58(1,216)$ & .001 \\
\hline Ambidextrous capability & 0.74 & 11.64 & .001 & & & & & \\
\hline${ }^{3}$ (Constant) & 0.005 & 0.01 & .99 & $.66^{\mathrm{a}}$ & .44 & .43 & $45.76(2,214)$ & $.001^{\mathrm{c}}$ \\
\hline Adaptive capability & 0.07 & 0.54 & .58 & & & & & \\
\hline Ambidextrous capability & 0.83 & 5.95 & .001 & & & & & \\
\hline${ }^{4}$ (Constant) & 2.21 & 6.11 & .001 & $.50^{\mathrm{a}}$ & .25 & .24 & $38.67(1,215)$ & .001 \\
\hline Social media agility & 0.46 & 6.21 & .001 & & & & & \\
\hline 5 (Constant) & 0.19 & 0.38 & .001 & $.65^{\mathrm{a}}$ & .42 & .41 & $85.47(1,216)$ & .001 \\
\hline Ambidextrous capability & 0.93 & 9.24 & .001 & & & & & \\
\hline${ }^{6}$ (Constant) & 0.08 & 0.18 & .85 & $.67^{\mathrm{a}}$ & .45 & .44 & $46.79(2,214)$ & $.001^{\mathrm{c}}$ \\
\hline Social media agility & 0.10 & 1.19 & .23 & & & & & \\
\hline Ambidextrous capability & 0.79 & 6.43 & .001 & & & & & \\
\hline 7 (Constant) & 2.98 & 11.54 & .001 & $.57^{\mathrm{a}}$ & .33 & .32 & $57.77(1,216)$ & $.001^{\mathrm{c}}$ \\
\hline Social media agility & 0.40 & 7.60 & .00 & & & & & \\
\hline
\end{tabular}

\section{Discussion, Conclusion, Recommendation, and Suggestion for Further Studies}

The study assessed the individual effect of adaptive capability and social media agility on business survival. Moreover, the study examined the mediating effect of ambidextrous marketing capability on the individual effect of adaptive capability and social media agility on business survival. Lastly, this study investigated how social media agility affects a firm's adaptive capability. The findings align with the hypotheses formulated in this study hence providing important implications for theory and practice. The result of the first hypotheses (1 and 3) suggested that individually, adaptive capability and social media agility positively and significantly affect business survival. These findings corroborate prior empirical studies (Chryssochoidis et al., 2016; Kelly et al., 2020; Martín-Rojas et al., 2020; Mehrabi et al., 2019; Zhu et al., 2017). The mediation hypothesis's result suggested that ambidextrous capability mediates the individual effect of adaptive capability and social media agility on business survival, respectively. By this result, the assumptions of the interactionist perspective of fit-as-mediator are upheld.

The dynamic capability promotes the ideology that firms desirous of achieving superior performance must develop and deploy unique internal and external competencies adaptable to a changing 
environment. All the predictor variables, adaptive capability, social media agility, and ambidextrous marketing capability in this study are developed by firms and possess dynamism attributes that can survive a dynamic environment. Also, by this study's results, the contingency theory of fit-as-mediator is strengthened because the effect-relationship between two variables is explained by introducing a third variable (ambidextrous marketing capability). This study strongly affirms this position with its results.

The contribution of this study to knowledge is in many ways. The study addressed the literature's identified gap, hence providing the body of knowledge with evidence of the boundary mechanism through which AC and SMA influence firm survival, how SMA enhanced AC, and how AMC mediates AC's individual relationship SMA on firm survival, respectively. Management seeking to channel resources to survive the post-COVID-19 pandemic will need to commit significant resources to reinvent AC, SMA, AMC. Also, this study, through its findings, draws relevance for the dynamic capability theory and consequently provided additional support for the significance of the framework through which firms faced with the turbulent environment can achieve business continuity. The contingency perspective explains the theoretical means through which a mediation effect can occur was tested in this study, and the results corroborated the contingency perspective of fit-as-mediator. This study's relevance in strategic management is equally noteworthy as it contributes to current literature in this field, pushing forward the frontier of knowledge. Consequent to these findings, the study recommends that firms should strengthen their adaptive capability infrastructure, develop a robust, agile social media interface, and continue to commit resources that will enhance connectivity with the market, supplier, and the customers (outside-in) as well as enhance internal organizational knowledge, skill, and ability (inside-out) to offer incremental and radical products and services to address changing market demand.

Like many studies, this study has limitations that must be acknowledged to provide opportunities for future studies. First of all, the study is a multiple industry analysis covering five countries, and while this may enhance the generalization of its findings, nevertheless, countries in the Middle East, Europe, Latin America, and many countries in Africa were not considered. This suggests that the generalizing of its findings should be with caution. Hence, future studies may consider a different context to see if the findings can be generalized. Furthermore, a comparative analysis of country by country, given this study's objectives, may present an exciting area of research. The adoption of a cross-sectional survey design equally suggests that the study cannot explain the causality in the dependent variable attributable to the independent and mediating variable over a long period. Future studies may consider a longitudinal study to explain causality with this study's variables over time. Although the factors investigated in this study are context-specific, other factors can influence a firm to survive. Hence, future studies may consider these other factors that can influence firm survival. Despite these limitations, this study provides vital empirical, theoretical, and practical implications for businesses regarding the deployment of ambidextrous marketing capability as the mechanism through which adaptive capability and social media agility can respectively influence firm survival. 


\section{References}

Akhtar, P., Khan, Z., Tarba, S., \& Jayawickrama, U. (2018). The Internet of Things, dynamic data and information processing capabilities, and operational agility. Technological Forecasting and Social Change, 136, 307-316.

Ali, A., Bahadur, W., Wang, N., Luqman, A., \& Khan, A. N. (2020). Improving team innovation performance: Role of social media and team knowledge management capabilities. Technology in Society, 61, 1-12.

Anning-Dorson, T. (2018). Customer involvement capability and service firm performance: The mediating role of innovation. Journal of Business Research, 86(4), 269-280.

Arokodare, M. A., Asikhia, O. U., \& Makinde, G. O. (2019). Strategic agility and firm performance: The moderating role of organisational culture. Business Management Dynamics, 9(3), 01-12.

Barney, J. B. (2014). How marketing scholars might help address issues in resource-based theory. Journal of the Academy of Marketing Science, 42(1), 24-26.

Baron, R. M., \& Kenny, D. A. (1986). The moderator-mediator variable distinction in social psychological research: Conceptual, strategic, and statistical considerations. Journal of Personality and Social Psychology, 51(6), 1173-1182.

Bullini-Orlandi, L., Zardini, A., \& Rossignoli, C. (2020). Organizational technological opportunism and social media: The deployment of social media analytics to sense and respond to technological discontinuities. Journal of Business Research, 112, 385-395. https://doi.org/10.1016/j.jbusres.2019.10.070

Carr, A., Drennan, J., \& Andrews, L. (2016). Measuring customer equity and managing the customer asset: An explanatory study in the Australian hotels. Journal of Marketing Management, 32(17-18), 16701700. https://doi.org/10.1080/0267257x.2016.1260043

Chong, W. K., Bian, D., \& Zhang, N. (2016). E-marketing services and e-marketing performance: the roles of innovation, knowledge complexity and environmental turbulence in influencing the relationship. Journal of Marketing Management, 32(12), 149-178.

Christodoulides, G., Michaelidou, N., \& Siamagka, N. (2019). Social media, content marketing and engagement strategies in B2B. Industrial Marketing Management, 81, 87-88.

Chryssochoidis, G., Dousios, D., \& Tzokas, N. (2016). Small firm adaptive capability, competitive strategy, and performance outcomes: Competing mediation vs. moderation perspectives. Strategic Change, 25(4), 441466. https://doi.org/10.1002/jsc.2073

Chuang, S. (2020). Co-creating social media agility to build strong customer-firm relationships. Industrial Marketing Management, 84, 202-211. https://doi.org/10.1016/j.indmarman.2019.06.012

Cochran, W. G. (1963). Sampling techniques. 2nd edition. New York: John Wiley and Sons, Inc.

Conduit, J., Matanda, M. J., \& Mavondo, F. T. (2014). Balancing the act: the implications of jointly pursuing internal customer orientation and external customer orientation. Journal of Marketing Management, 30(13-14), 1320-1352.

Day, G. S. (2011). Closing the marketing capabilities gap. Journal of Marketing, 75(4), 183-195.

Day, G. S. (2014). An outside-in approach to resource-based theories. Journal of the Academy of Marketing Science, 42(1), 2728.

Day, G. (2020). The Yin and Yang of outside-in thinking. Industrial Marketing Management, 88, 8486. https://doi.org/10.1016/j.indmarman.2020.04.025

Day, G. S., \& Moorman, C. (2010). Strategy from the outside-in: Profiting from customer value. New York: McGraw-Hill.

Eshima, Y., \& Anderson, B. S. (2016). Firm growth, adaptive capability, and entrepreneurial orientation. Strategic Management Journal, 38(3), 770-779. https://doi.org/10.1002/smj.2532

Frau, M., Moi, L., \& Cabiddu, F. (2020). Outside-in, inside-out, and blended marketing strategy approach: A longitudinal case study. International Journal of Marketing Studies, 12(3), 1-13. https://doi.org/10.5539/ijms.v12n3p1

Garrido-Moreno, A., García-Morales, V., King, S., \& Lockett, N. (2020). Social media use and value creation in the digital landscape: A dynamic-capabilities perspective. Journal of Service Management, ahead-of-print (ahead-ofprint). https://doi.org/10.1108/josm-09-2018-0286

Grant, A. (1996). Marketing: The need to contribute to overall business effectiveness. Journal of Marketing Practice: Applied Marketing Science, 2(3), 7-11.

Hardwick, J., \& Anderson, A. R. (2019). Supplier-customer engagement for collaborative innovation using video conferencing: A study of SMEs. Industrial Marketing Management, 80, 43-57.

Harrigan, P., Miles, M. P., Fang, Y., \& Roy, S. K. (2020). The role of social media in the engagement and information processes of social CRM. International Journal of Information 102151. https://doi.org/10.1016/j.ijinfomgt.2020.102151

Ho, H., \& Lu, R. (2015). Performance implications of marketing exploitation and exploration: Moderating role of supplier collaboration. Journal of Business Research, 68(5), 1026-1034. https://doi.org/10.1016/j.jbusres.2014.10.004 
Ho, H., Osiyevskyy, O., Agarwal, J., \& Reza, S. (2020). Does ambidexterity in marketing pay off? The role of absorptive capacity. Journal of Business Research, 110, 65-79. https://doi.org/10.1016/j.jbusres.2019.12.050

Hou, J., \& Chien, Y. (2010). The effect of market knowledge management competence on business performance: A dynamic capabilities perspective. International Journal of Electronic Business Management, 8(2), 96-109. https://doi.org/10.1016/j.jbusres.2019.12.050

Josephson, B. W., Johnson, J. L., \& Mariadoss, B. J. (2016). Strategic marketing ambidexterity: Antecedents and financial consequences. Journal of the Academy of Marketing Science, 44(4), 539-554.

Junni, P., Sarala, R., Taras, V., \& Tarba, S. (2013). Organizational ambidexterity and performance: A meta-analysis. Academy of Management Perspectives, 27(4), 299-312.

Kaur, V., \& Mehta, V. (2017). Dynamic capabilities for competitive advantage: A comparative study of IT multinationals in India. Paradigm, 21(1) 31-51.

Kaur, J., Chahal, H., \& Gupta, M. (2018). Re-investigating market orientation and environmental turbulence in marketing capability and business performance linkage: A structural approach. Business Analytics, 8(5), 145-168.

Kelly, N., Kelliher, F., Power, J., \& Lynch, P. (2020). Unlocking the niche potential of senior tourism through micro-firm ownermanager adaptive capability development. Tourism Management, 79, 104081. https://doi.org/10.1016/j.tourman.2020.104081

Kelliher, F., Kearney, A., \& Harrington, D. (2018). Managing innovation in the hospitality micro firm: A framework for sensing, seizing and reconfiguring dynamic capabilities. Hospitality and Society, 8(2), 159-178.

Kim, W., Kim, H., \& Hwang, J. (2020). Sustainable growth for the self-employed in the retail industry based on customer equity, customer satisfaction, and loyalty. Journal of Retailing and Consumer Services, 53, 101963. https://doi.org/10.1016/j.jretconser.2019.101963

Koponen, J., Julkunen, S., \& Asai, A. (2019). Sales communication competence in international B2B solution selling. Industrial Marketing Management, 82, 238-252.

Kozlenkova, I. V., Samaha, S. A., \& Palmatier, R. W. (2014). Resource-based theory in marketing. Journal of the Academy of Marketing Science, 42(1), 1-21.

Kumar, V. (2015). Evolution of marketing as a discipline: What has happened and what to look out for. Journal of Marketing, 79(1), 1-9.

Laaksonen, O., \& Peltoniemi, M. (2016). The essence of dynamic capabilities and their measurement. International Journal of Management Reviews, 20(2), 184-205.

Li, M., Teng, H., \& Chen, C. (2020). Unlocking the customer engagement-brand loyalty relationship in tourism social media: The roles of brand attachment and customer trust. Journal of Hospitality and Tourism Management, 44, 184192. https://doi.org/10.1016/j.jhtm.2020.06.015

Lu, Y., Zhou, L., Bruton, G., \& Li, W. (2010). Capabilities as a mediator linking resources and the international performance of entrepreneurial firms in an emerging economy. Journal of International Business Studies, 41, 419-436.

Martín-Rojas, R., García-Morales, V. J., Garrido-Moreno, A., \& Salmador-Sánchez, M. P. (2020). Social media use and the challenge of complexity: Evidence from the technology sector. Journal of Business Research. https://doi.org/10.1016/j.jbusres.2019.12.026

Mehrabi, H., Coviello, N., \& Ranaweera, C. (2019). Ambidextrous marketing capabilities and performance: How and when entrepreneurial orientation makes a difference. Industrial Marketing Management, 77, 129142. https://doi.org/10.1016/j.indmarman.2018.11.014

Mohammed, N. I., Norshahrizan, B. N., \& Wan-Ahmad, B. W. (2017). Innovation capability and firm performance relationship: A study of partial least square-structural equation modelling. International Journal of Organisation and Business Excellence, 2(1), 1-12.

Monferrer, D., Blesa, A., \& Ripollés, M. (2015). Born globals trough knowledge-based dynamic capabilities and network market orientation. Business Research Quarterly, 18(1), 18-36.

Mpandare, M., \& Li, G. (2020). Utilising enterprise social media for product innovation: The role of market orientation. Sustainability, 12(9), 3913. https://doi.org/10.3390/su12093913

$\mathrm{Mu}, \mathrm{J}$. (2015). Marketing capability, organisational adaptation and new product development performance. Industrial Marketing Management, 49(7), 151-166.

$\mathrm{Mu}$ J. (2017). Dynamic capability and firm performance: The role of marketing capability and operations capability. IEEE Transactions on Engineering Management, 64(4), 554-565.

Mu, J., Bao, Y., Sekhon, T., Qi, J., \& Love, E. (2018). Outside-in marketing capability and firm performance. Industrial Marketing Management, 75, 37-54. https://doi.org/10.1016/j.indmarman.2018.03.010 
Mukhtar, B., Rosli, M., \& Azizi, H. (2017). The moderating role of environmental turbulence on the relationship between organisational learning and firm innovativeness. Journal of Management Research and Review, 7(2), 148-159.

Murphy, M., \& Sashi, C. M. (2018). Communication, interactivity, and satisfaction in B2B relationships. Industrial Marketing Management, 68, 1-12.

Musarra, G., \& Morgan, N. A. (2020). Outside-in marketing: Renaissance and future. Industrial Marketing Management, 89, 98101. https://doi.org/10.1016/j.indmarman.2020.01.001

Najafi-Tavani, S., Najafi-Tavani, Z., Naudé, P., Oghazi, P., \& Zeynaloo, E. (2018). How collaborative innovation networks affect new product performance: Product innovation capability, process innovation capability, and absorptive capacity. Industrial Marketing Management, 73(4), 193-205.

Nijssen, E. J., \& Ordanini, A. (2020). How important is alignment of social media use and R\&D-marketing cooperation for innovation success? Journal of Business Research, 116, 1-12. https://doi.org/10.1016/j.jbusres.2020.04.056

Nunan, D., Sibai, O., Schivinski, B., \& Christodoulides, G. (2018). Reflections on "social media: Influencing customer satisfaction in B2B sales" and a research agenda. Industrial Marketing Management, 75, 31-36.

Ogilvie, J., Agnihotri, R., Rapp, A., \& Trainor, K. (2018). Social media technology use and salesperson performance: A two study examination of the role of salesperson behaviors, characteristics, and training. Industrial Marketing Management, 75, 55-65

Oktemgil, M., \& Greenley, G. (1997). Consequences of high and low adaptive capability in UK companies. European Journal of Marketing, 31(7), 445-466. https://doi.org/10.1108/03090569710176619

Onamusi, A. B. (2020). Knowledge acquisition capability, strategic response capability, and organisational performance: A mediated analysis. Business Excellence and Management, 10(3), 47-60.

Quach, S., Thaichon, P., Lee, J., Weaven, S., \& Palmatier, R. W. (2020). Toward a theory of outside-in marketing: Past, present, and future. Industrial Marketing Management, 89, 107-128. https://doi.org/10.1016/j.indmarman.2019.10.016

Soludo, C. C. (2020). Can Africa afford COVID-19 lockdowns? Retrieved from Proshare website. https://www.proshareng.com/news/NIGERIA\%20ECONOMY/

Sun, W., Price, J., \& Ding, Y. (2019). The longitudinal effects of internationalisation on firm performance: The moderating role of marketing capability. Journal of Business Research, 95(10), 326-337.

Swafford, P. M., Ghosh, S., \& Murthy, N. (2008). Achieving supply chain agility through IT integration and flexibility. International Journal of Production Economics, 116(2), 288-297.

Tan, F. T. C., Tan, B., Wang, W., \& Sedera, D. (2017). IT-enabled operational agility: An interdependencies perspective. Information and Management, 54(3), 292-303.

Teece, D. J. (2014a). A dynamic capabilities-based entrepreneurial theory of the multinational enterprise. Journal of International Business Studies, 45(1), 8-37.

Teece, D. J., Pisano, G., \& Shuen, A. (1997). Dynamic capabilities and strategic management. Strategic Management Journal, 18(7), 509-533.

Wang, Y., Zhang, M., Tse, Y. K., \& Chan, H. K. (2020). Unpacking the impact of social media analytics on customer satisfaction: Do external stakeholder characteristics matter? International Journal of Operations and Production Management, ahead-of$\operatorname{print}($ ahead-of-print). https://doi.org/10.1108/ijopm-04-2019-0331

Wei, L., \& Lau, C. (2010). High performance work systems and performance: The role of adaptive capability. Human Relations, 63(10), 1487-1511. https://doi.org/10.1177/0018726709359720

Wei, Z., Yi, Y., \& Guo, H. (2014). Organisational learning ambidexterity, strategic flexibility, and new product development. Journal of Product Innovation Management, 31(4), 832-847.

World Health Organization. (2020). World could face multiple famines of biblical proportions due to COVID-19. Retrieved from The Economist Times website. https://economictimes.indiatimes.com/news/international/world-news/world

Wu, J., \& Vahlne, J. (2020). Dynamic capabilities of emerging market multinational enterprises and the Uppsala model. Asian Business and Management, 1-25. https://doi.org/10.1057/s41291-020-00111-5

Zhu, W., Su, S., \& Shou, Z. (2017). Social ties and firm performance: The mediating effect of adaptive capability and supplier opportunism. Journal of Business Research, 78, 226-232. 